\title{
Family Physicians' Quality Interventions and Perfor- mance Improvement Through the ABFM Diabetes Performance in Practice Module
}

Lars E. Peterson, $M D, P b D$

Brenna E. Blackburn, MPH

James C. Puffer, MD

Robert L. Pbillips, Jr, MD, MSPH

The American Board of Family Medicine, Lexington, Kentucky
Conflicts of interest: authors report none.

\section{CORRESPONDING AUTHOR}

Lars E. Peterson, MD, PhD

American Board of Family Medicine 1648 McGrathiana Pkwy, Suite 550 Lexington, KY 40511-1247 lpeterson@theabfm.org

\begin{abstract}
PURPOSE Practice performance assessment is the fourth requirement of Maintenance of Certification for Family Physicians (MC-FP). American Board of Family Medicine (ABFM) diplomates have many options for completing Part 4 requirements, including Web-based Performance in Practice Modules (PPMs) developed by the ABFM. Our objective was to describe the actions and outcomes of family physicians who completed the ABFM diabetes PPM.
\end{abstract}

METHODS We undertook a descriptive study of all diabetes PPMs completed by physicians in the 50 United States and Washington, DC, from 2005 to October 2012. Successful completion required quality measure abstraction from 10 patient charts before and after a plan-do-study-act cycle improvement effort. We used descriptive statistics to assess physician demographics and quality outcomes.

RESULTS Family physicians completed 7,924 diabetes qualitative improvement modules. Their mean age was 48.2 years, they had practiced a mean of 13.8 years, and three-fourths lived in urban areas (76.9\%). Nearly one-half selected diabetic foot examination or eye examination as their quality improvement measure. Performance on all quality measures improved. Significant improvement was seen in rates of hemoglobin $A_{1 c}$ control $(<7.0 \% ; 57.4 \%$ to $61.3 \%)$, blood pressure control (<130/90 mm Hg; $53.3 \%$ to $56.3 \%)$, foot examinations $(68.0 \%$ to $85.8 \%)$; and retina examinations (55.5\% to $71.1 \%)$. The most common interventions were standing orders (51.6\%) and patient education (37.1\%).

CONCLUSIONS Family physicians participating in MC-FP implemented improvement projects and showed quality improvements in caring for patients with diabetes. Emphasis on quality of care by payers will increasingly require physicians to embrace quality measurement and improvement.

Ann Fam Med 2014;17-20. doi:10.1370/afm.1592.

\section{INTRODUCTION}

M easurement of the quality of care delivered in practice is becoming increasingly important. Payers and policy makers are trying to align forces for quality improvement by tying payments to quality measurement and the quality of care delivered., ${ }^{1,2}$ For example, insurance companies are using physician quality measures to steer patients to high-quality clinicians. ${ }^{3}$

In 2002, all American Board of Medical Specialties boards adopted maintenance of certification with the goal of improving the quality of health care. There is an opportunity to align maintenance of certification with quality reporting to both reinforce quality incentives and reduce reporting burden. ${ }^{4}$ The American Board of Family Medicine (ABFM) was one of the first boards to fully implement maintenance of certification. ${ }^{5,6}$ Part 4 of the Maintenance of Certification for Family Physicians (MC-FP) process requires physicians to measure the quality of their care, report it, plan and execute an intervention, and then re-measure and report outcomes. Recognizing that many diplomates were not familiar with the 
science of quality improvement, Part 4 modules- the Performance in Practice Modules (PPMs) - were developed to include quality improvement tutorials and resources. Through MC-FP, family physicians complete a Part 4 activity at least once every 3 years, reinforcing their knowledge and use of quality improvement. The objective of our study was to characterize the actions and outcomes of the ABFM diplomates who had completed a diabetes PPM.

\section{METHODS}

\section{Quality Measures in the Diabetes Performance in Practice Module}

To complete their Part 4 requirement for diabetes, diplomates abstract measures for at least 10 patients with diabetes. The ABFM diabetes PPM uses measures endorsed by the National Quality Forum, including (1) hemoglobin $A_{1 c}$ measurement; (2) foot examination, (3) assessment of the presence of microalbuminuria, (4) smoking cessation counseling, (5) retina examination, (6) low-density lipoprotein (LDL) measurement, and (7) blood pressure measurement. Quality measures include a patient survey using a questionnaire that asked the following: (1) Have you had your $A_{1 c}$ checked in the last 6 months? (2) Did the doctor check your blood pressure during today's visit? (3) Do you know your goal blood pressure? (4) Has your doctor checked your urine for signs of diabetic kidney disease this year? (5) If you smoke, has your doctor talked to you about quitting? (6) Have you had an eye exam in the last 12 months? (7) Have you had your cholesterol checked in the past year?

\section{Completion of Performance in Practice Module} Completion of the PPM is done online and allows clinic support staff to enter quality data without access to the confidential physician portfolio information. To protect against legal discoverability of quality data, limited physician demographic information is copied to the PPM database. Once the PPM is complete, the link between the physician and PPM data is broken. This necessary step makes it difficult to study the relationship between PPM outcomes and physician or practice characteristics.

The PPM process resembles a plan-do-study-act (PDSA) cycle. First, the physician abstracts data from 10 patient charts. Questionnaires are administered to the patients whose charts are abstracted to assess knowledge of their health goals and current disease status. After entry of the abstracted and survey data, the physician is provided a "quality dashboard" showing their performance on all 7 diabetes indicators compared with physicians who previously completed the PPM.
Next, physicians select 1 or more quality measures for improvement and create a quality improvement plan using at least 2 of the following categories from the Chronic Care Model: self-management support, delivery system design, decision support, clinical information systems, health system, and community resources and policies. ${ }^{7}$ At least 1 intervention must be selected within the selected Chronic Care Model category. The PPM provides many intervention options with links to more information and examples. After physicians implement their interventions, they repeat the abstraction/ survey/data-entry cycle and are provided with preintervention and postintervention comparisons.

\section{Physician Demographic Variables and Performance in Practice Module Data}

As stated previously, to protect against legal discoverability, the link between the physician and the PPM is broken upon completion of the module. In so doing, physician demographic variables are restricted to age (calculated from date of birth to the date the PPM was started), sex, ZIP code, date of residency graduation, years in practice, and number of recertifications.

\section{Analytic Strategy}

We analyzed data from all diabetes PPMs completed from 2005 to October 2012. We excluded physicians with incomplete quality data, those in residency, and those not residing in the 50 United States or Washington, DC. We determined rurality of each practice by linking ZIP code to the Rural-Urban Commuting Area codes (RUCAs) version 2.0. ${ }^{8}$

We used descriptive statistics to describe the data. Statistical tests for differences between rates of preintervention and postintervention measures were done using either $t$ tests or $\chi^{2}$ tests. All analyses were conducted in SAS 9.2 (SAS Institute).

The chair of the American Academy of Family Physicians Institutional Review Board assessed that this study did not constitute human subjects research based on the use of previously de-identifed data.

\section{RESULTS}

We found 8,037 completed PPMs. After excluding modules done by physicians not residing in the 50 United States or Washington, DC $(\mathrm{n}=31)$, those with missing demographic variables $(n=28)$, those who could not be linked to a RUCA code $(n=41)$, and those with incomplete quality data $(n=13)$, our final sample consisted of 7,924 completed modules (Table 1). The mean age of physicians completing the modules was 48.2 years, $61.9 \%$ were male, and they had a mean of 13.8 years in practice. The mean time to 
complete the module was 184.5 days with a standard deviation of 168.2 days.

Performing a diabetic foot examination and documenting a retina examination were the most frequently

\section{Table 1. Demographics of Physicians Completing the Diabetes Quality Improvement Module}

\begin{tabular}{lc}
\hline Variable & Value \\
\hline Age, y, mean (SD) & $48.2(9.2)$ \\
Sex, male, \% & 61.9 \\
Years in practice, mean (SD) & $13.8(9.1)$ \\
Number of recertifications, mean (SD) & $1.9(1.4)$ \\
Days to complete PPM, mean (SD) & $184.5(168.2)$ \\
Practice location, \% & \\
Urban & 76.9 \\
Large rural & 11.5 \\
Small rural & 7.8 \\
Isolated & 3.9 \\
\hline PPM = Performance in Practice module. & \\
Note: there were 7,924 completed modules.
\end{tabular}

Table 2. Physician Quality Measures Before and After the Intervention

\begin{tabular}{lcc}
\hline Measure & Before & After $^{\text {a }}$ \\
\hline Hemoglobin $\mathrm{A}_{1 c}$ mean (SD), \% & $7.2(1.5)$ & $7.1(1.3)$ \\
Hemoglobin $\mathrm{A}_{\mathrm{lc}}$ levels in control $(<7.0 \%), \%$ & 57.4 & 61.3 \\
Foot examination performed, \% & 68.0 & 85.8 \\
Microalbuminuria assessed, \% & 74.5 & 88.3 \\
Smoking cessation counseling, \% & 87.1 & 93.1 \\
Retina examination performed, \% & 55.5 & 71.1 \\
Low-density lipoprotein cholesterol, mean (SD), mg/dL & $94.7(33.9)$ & $93.7(31.5)$ \\
Low-density lipoprotein cholesterol levels <100 mg/dL, \% & 63.1 & 64.6 \\
Systolic blood pressure, mm Hg (SD) & $128.9(15.2)$ & $127.9(14.3)$ \\
Diastolic blood pressure, mm Hg (SD) & $75.4(9.8)$ & $75.2(9.4)$ \\
Systolic blood pressure <130 mm Hg and diastolic blood & 53.3 & 56.3 \\
pressure <90 mm Hg, \% & & \\
\hline a All significant at $P<.01$. & & \\
\hline
\end{tabular}

Table 3. Patient Quality Measures Before and After the Intervention

\begin{tabular}{lcc}
\hline Patient-Reported Measure & Before, \% & After, \%a \\
\hline Have you had your hemoglobin $\mathrm{A}_{1 \mathrm{c}}$ (a test of how much & 92.4 & 95.9 \\
$\quad$ sugar is in your blood) checked in the last 6 months? & 76.5 & 89.7 \\
Has your doctor checked your feet in the last 6 months? & 99.6 & 99.8 \\
$\begin{array}{l}\text { When you see your doctor, is your blood pressure checked? } \\
\text { Do you know your goal blood pressure (the blood pressure }\end{array}$ & 77.0 & 85.9 \\
$\quad$ you should have for good health)? & 77.2 & 87.4 \\
Has your doctor tested your urine for signs of diabetic kid- & & 79.4 \\
$\quad$ ney disease this year? & 69.5 & 95.2 \\
$\quad$ Have you had an eye exam by an eye care professional in & & 96.6 \\
$\quad \begin{array}{l}\text { If you smoke, has your doctor talked to you about quitting? } \\
\text { Have you had your cholesterol checked in the past year? }\end{array}$ & 91.1 & \\
\hline all significant at $P<.01 .0$ & & \\
\hline
\end{tabular}

chosen quality measures for improvement, both chosen by nearly one-half of physicians ( $46.1 \%$ each). Testing for microalbuminuria was third most frequent (29.8\%) measure chosen. Checking hemoglobin $\mathrm{A}_{1 \mathrm{c}}$ or lipid levels, assessing blood pressure control, and counseling for smoking cessation were all selected by less than $15 \%$ of physicians. For more than one-half of physicians, 2 Chronic Care Model categories were chosen for the intervention strategy: self-management support and delivery system design. Interventions chosen by more than $30 \%$ of physicians were standing orders $(51.6 \%)$, patient education (37.1\%), and patient care cards (30.3\%).

All quality measures improved after the intervention (Table 2). Foot examination documentation increased from $68.0 \%$ to $85.8 \%$, and retina examination documentation increased from $55.5 \%$ to $71.1 \%$. Testing for microalbuminuria rose from $74.5 \%$ to $88.3 \%$. Small but statistically significant increases were seen in the percentage of patients having a hemoglobin $\mathrm{A}_{1 \mathrm{c}}$ value at less than $7.0 \%$ (57.4\% to $\left.61.3 \%\right)$, having their blood pressure under control (53.3\% to $56.3 \%$ ), and having their LDL cholesterol at less than $100 \mathrm{mg} / \mathrm{dL}$ $(63.1 \%$ to $64.6 \%)$. The percentage of patients reported having their feet examined in the last 6 months increased from $76.5 \%$ to $89.7 \%$, and those reporting a retina examination increased from $69.5 \%$ to $79.4 \%$ (Table 3 ).

\section{DISCUSSION}

We found that family physicians successfully executed quality improvement projects through the MC-FP process. These projects were associated with significant and often meaningful improvements, whether measured and reported by physicians or reported directly by patients. We found that most family physicians chose to improve on the quality measures for which they were performing poorly but were largely able to demonstrate improvements in quality for most measures. The majority also chose measures over which they had the most direct control (feet and retina examinations) and that may suffer most from poor capture in electronic health records. 
Each quality improvement project is unique to the context of the practice where it is implemented. Some changes, such as standing orders for blood pressure measurement, may result in dramatic and rapid changes. Other interventions, such as improving hemoglobin $\mathrm{A}_{1 \mathrm{c}}$ and LDL values, which are more important in reducing mortality and morbidity, may require intensive time and effort to result in a change. In support of this possibility, we found a mean time to complete the PPM to be 184 days (6 months), suggesting that many physicians were implementing strategies that required time to have an effect on care and show outcomes. On the other end, a sizeable minority of PPM's were completed in 1 to 3 weeks, which may suggest a rapid-cycle improvement strategy. Regardless of the length of time the intervention took, we were unable to measure sustained improvement because we could not link the PPM to other PPMs or quality improvement data from the physicians studied. More frequent assessment, protection from data discoverability that allows data to remain identified, or both, may make it possible to measure sustained improvement.

Our study used physician self-reported data to assess quality of care. Although physicians are not formally trained in chart abstraction, they routinely interrogate charts for pertinent clinical information during patient encounters. Prior work showed that practices can reliably and accurately abstract and report data from their medical records. ${ }^{9}$ A potential limitation of our study is that physicians may have selectively chosen patients in an effort to boost their quality measures. Previous research, however, found that patient selection by physicians engaged in maintenance of certification projects was unbiased, as the primary goals were educational. ${ }^{10}$ Corroboration of results from patient surveys argue against such cherry-picking.

Other limitations may also potentially affect our findings. First, because of concerns about discoverability, we were unable to link other ABFM data elements, such as past PPMs or self-assessment modules taken or practice information. Second, physicians may complete the diabetes PPM multiple times, a possibility we were unable to determine because of delinking of data.

Our study of nearly 8,000 diabetes quality improvement projects by family physicians found that these projects were largely successful in improv- ing the quality of care and adds to the evidence base for integration of quality improvement into practice. Leveraging MC-FP to improve the quality of care family physicians deliver may be vital in meeting the triple aim of reducing costs, raising quality of care, and improving health. ${ }^{11}$

To read or post commentaries in response to this article, see it online at www.annfammed.org/content/12/1/17.

Submitted March 14, 2013; submitted, revised, July 22, 2013; accepted August 2, 2013.

Key words: family physicians; diabetes mellitus; quality of health care; quality improvement

Previous presentation: Podium presentation at AcademyHealth Annual Research Meeting, Baltimore, Maryland, June 23-25, 2013.

\section{References}

1. Rosenthal MB, Fernandopulle R, Song HR, Landon B. Paying for quality: providers' incentives for quality improvement. Health Aff (Millwood). 2004;23(2):127-141.

2. Mayes R. Moving (realistically) from volume-based to value-based health care payment in the USA: starting with medicare payment policy. J Health Serv Res Policy. 2011;16(4):249-251.

3. Chernew ME, Mechanic RE, Landon BE, Safran DG. Private-payer innovation in Massachusetts: the 'alternative quality contract'. Health Aff (Millwood). 2011;30(1):51-61.

4. Conway PH, Cassel CK. Engaging physicians and leveraging professionalism: a key to success for quality measurement and improvement. JAMA. 2012;308(10):979-980.

5. Xierali IM, Rinaldo JC, Green LA, et al. Family physician participation in maintenance of certification. Ann Fam Med. 2011;9(3):203-210.

6. Puffer JC, Bazemore AW, Newton WP, Makaroff L, Xierali IM, Green LA. Engagement of family physicians seven years into maintenance of certification. J Am Board Fam Med. 2011;24(5):483-484.

7. Wagner EH, Austin BT, Von Korff M. Organizing care for patients with chronic illness. Milbank Q. 1996;74(4):511-544.

8. WWAMI Rural Health Research Center. Rural-Urban Commuting Area Codes (RUCAs). http://depts.washington.edu/uwruca/. Accessed Jun 5, 2013.

9. Holmboe ES, Meehan TP, Lynn L, Doyle P, Sherwin T, Duffy FD. Promoting physicians' self-assessment and quality improvement: the ABIM diabetes practice improvement module. J Contin Educ Health Prof. 2006;26(2):109-119.

10. Duffy FD, Lynn LA, Didura $H$, et al. Self-assessment of practice performance: development of the ABIM Practice Improvement Module (PIM). J Contin Educ Health Prof. 2008;28(1):38-46.

11. Berwick DM, Nolan TW, Whittington J. The triple aim: care, health, and cost. Health Aff (Millwood). 2008;27(3):759-769. 